\title{
A preliminary framework to estimate and disclose ex-ante cost of capital for (fair) valuation
}

\section{Josilmar Cordenonssi Cia*}

Universidade Presbiteriana Mackenzie,

Av. Paulista, 1195 AP. 141, CEP: 01311-922,

São Paulo/SP, Brazil

Email: josilmar@mackenzie.br

*Corresponding author

\section{Joanília Neide de Sales Cia}

Universidade de São Paulo,

Av. Paulista, 1195 AP. 141, CEP: 01311-922,

São Paulo/SP, Brazil

Email: joanilia@usp.br

\section{Luiz Carlos Jacob Perera}

Universidade Presbiteriana Mackenzie,

Rua da Consolação, 896, CEP: 01302-907,

São Paulo/SP, Brazil

Email: jperera@mackenzie.br

\begin{abstract}
Fair-value accounting is usually seen as a rule to mark assets to market. While the market was bullish, there was little concern about the implications of a potential downside risk of fair value rules. But with the current world financial crisis triggered by US subprime loans default, pressure surged for it is simply extinction or at least for more flexibility to apply what 'fair' should really mean according to managers' judgment. Critics of fair-value (mark-to market) accounting raise the question that in some moments market prices decouple from the 'fundamentals' and using it as the value reference can distort financial statements. In other words, they posit that market are not always efficient, markets are prone to positive and negative price bubbles. This is a preliminary work that aims to estimate ex-ante cost of capital (or expected rate of return) using market data and some parameters, like expected equity market risk-premium, its volatility and an average relative risk-aversion of a representative agent. In other words, the main objective is to establish a framework of assumptions, in order to do and disclose inherently subjective estimates of equity market portfolio (or index) ex-ante expected rate of return, in a theoretical coherent manner.
\end{abstract}

Keywords: fair-value; cost of capital; CAPM; risk-aversion; expected utility theorem.

Reference to this paper should be made as follows: Cia, J.C., Cia, J.N.S. and Perera, L.C.J. (2016) 'A preliminary framework to estimate and disclose ex-ante cost of capital for (fair) valuation', Int. J. Multivariate Data Analysis, Vol. 1, No. 1, pp.61-75. 
Biographical notes: Josilmar Cordenonssi Cia is a Professor of Finance at the Universidade Presbiteriana Mackenzie in São Paulo, Brazil. His main topics of research are asset valuation, intertemporal optimisation, and equity premium puzzle.

Joanília Neide de Sales Cia is a Professor of Financial Accounting at the Universidade de São Paulo, Brazil. Her main interests of research are accounting of insurance and financial institutions.

Luiz Carlos Jacob Perera is a Professor of finance at the Universidade Presbiteriana Mackenzie, in São Paulo, Brazil. His main topics of research are business and sustainability, banking, risk management and mergers and acquisitions.

This paper is a revised and expanded version of a paper entitled 'A preliminary framework to estimate and disclose ex-ante cost of capital for (fair) valuation' presented at III Congresso IAAER-ANPCONT, São Paulo, Brazil, 10-12 June 2009.

\section{Introduction}

Since August 2007, and especially after the collapse of Lehman Brothers in September 2008, world financial markets suffered a breathtaking nosedive. Many financial professionals claimed that today market value of stocks, bonds and exchange rates are decoupled from fundamentals.

The lack of confidence on market prices, and consequently on market efficiency, has put bigger pressure on fair-value accounting rules. Some say that mark-to-market rule (SFAS 157) is one of the root causes of the current financial crisis, others say though not being responsible to trigger the crisis it is a pro-cyclical factor, amplifying the shock waves and preventing any smooth price adjustment.

Plantin et al. (2008a, 2008b) point that fair-value accounting do incentive managers to keep assets when their prices are high and offload them the fastest as possible when prices start to fall, causing this pro-cyclic effect. It is worth to highlight that these authors have not taken into account the regulatory capital requirement into their model. On the other hand, historical cost regime is also inefficient because it ignores market prices information.

Many professional and academics suggest that fair-value accounting instead of taking market prices as 'fair', should be the result of discounting asset's expected future cash-flows by "factors that are an average of past observed discount factors over a period that is longer than the time it takes to normally arrange a sale for a non-financially constrained firm" (Plantin et al., 2008a).

In the debt market it is possible to observe the past discount factors, but in the equity market you have to use a model. The capital asset pricing model (CAPM) probably is the most used model to estimate companies' cost of equity. But to use it properly it is necessary to input observable and non-observable variables, as we can see in its basic equation:

$$
E\left(k_{i}\right)=k_{f}+\beta\left[E\left(k_{M}\right)-k_{f}\right]
$$


The risk-free rate of return $\left(k_{f}\right)$ is observable; it is basically the yield of a treasury bond. It is only necessary to select the Treasury bond duration which matches most to investor's time horizon. A greater challenge is to assess the expected market portfolio rate of return $\left[E\left(k_{M}\right)\right]$, which is not observable. In the US market (and many other countries'), professionals may input directly the historical average market risk-premium $\left[E\left(k_{M}\right)-k_{f}\right]$, which ranges between 4 to $6 \%$ in annual basis (Campbell et al., 1997). Doing so they avoid doing guesswork, but they are implicitly assuming that the market will behave in the future similarly to the past.

Nonetheless, not every national capital market shows a positive historical equity risk premium. The Brazilian market is an example. Many studies show that its average historical equity risk premium is negative. Figure 1 shows the evolution of the São Paulo Stock Exchange Index (IBOVESPA), which is generally used as the proxy for market portfolio, and the risk-free rate (SELIC).

Figure 1 Evolution of the São Paulo Stock Exchange Index (IBOVESPA) against the Brazilian risk free rate (SELIC)

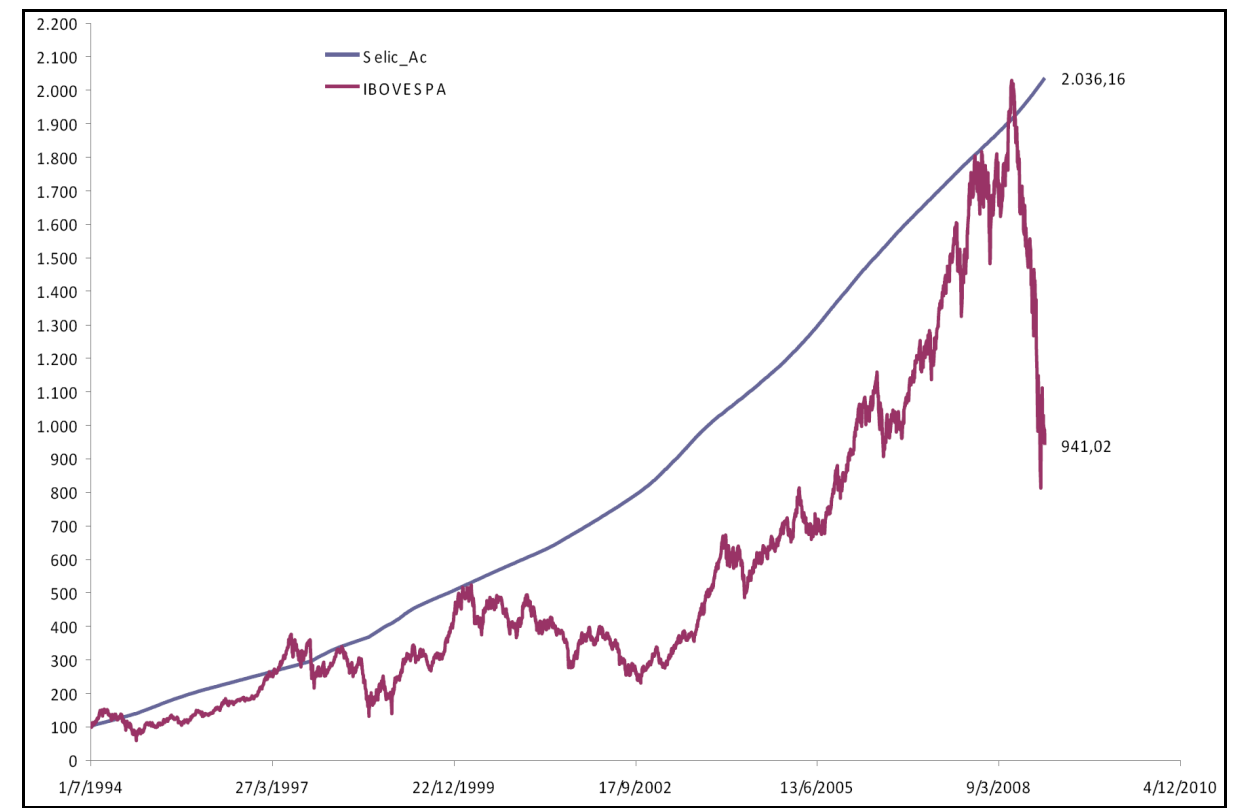

Note: Base $=100$ in 1 July 1994, last quotation 18 November 2008.

The base of the series is 100 in 1 July 1994, the day when the current national currency was launched along with a stabilisation plan. Before this date Brazilians had to cope with an inflation of four digits, more than $2,000 \%$ per year. Nowadays the inflation rate in Brazil is expected to reach $6 \%$ or $6.5 \%$ in 2008 , which is considered high but still within the tolerance band of 200 basis points above or below the central target, which is currently $4.5 \%$. Usually the Central Bank is able to manage to control inflation near the target. 
In spite of having controlled the inflation rate and even after receiving investment grade from major international rating agencies, the Brazilian Treasury continues to pay one of the highest interest rate in the world. The overnight nominal interest rate is around $13.75 \%$ in annual basis. And in addition to that, a significant part of the government debt is in floating rate bonds indexed to overnight rates, which is called SELIC interest rate. Thus in Brazil, great part of the interest rate risk is bore by the Treasury, and investors can get rid of interest rate risk with no 'financial engineering'.

Many academics in Brazil argue that SELIC is too high (today is $13.75 \%$ nominally, and around $7.75 \%$ in real terms) to be considered 'free of risk'. We understand this argument, but since it is possible to people invest in these floating rate bonds, it must take part in the opportunity cost of capital of holding stocks.

Assuming that Brazilians investors (and foreigners who invest in Brazilian stocks) are rational and risk averse, the ex-ante expected equity rate of return must be higher than the risk-free rate. How can be estimated the so-called ex-ante risky portfolio rate of return, based on the same past market data which shows us a negative ex-post average risk-premium?

Answering to this question is the main objective of this paper. We deduce a model based on expected utility theorem (Von Neumann and Morgenstern, 1944) to estimate the equity market portfolio rate of return.

\section{Expected utility theorem}

The expected utility theorem implies that people avoid taking part in fair games. Fair games mean that price of the bet is equal to the expected prise, i.e., the prise times the probability of occurrence.

In words, the main implication of the expected utility theorem is that one's utility (satisfaction) of wealth is not a function of how much wealth $(W)$ he or she expects to have in a given time $(U[E(W)])$, but how much he or she expects to enjoy $(E[U(W)])$ this wealth.

Assuming agents are risk-averse, the greater the risk of their wealth, the lesser is their utility (satisfaction), because their expectation of enjoying it diminishes even if the expected value of their wealth does not change.

In the case of a risk-neutral person, it does not matter how risky is his or her portfolio, only expected wealth determines utility, i.e., $E[U(W)]=U[E(W)]$. But in financial economics it is assumed that agents are risk-averse, which implies Jensen's inequality:

$$
E[U(W)]<U[E(W)]
$$

For this relation be always true for any level of wealth $(W)$ the utility function must be concave. In other words, utility of wealth always goes up when wealth increases $\left[U^{\prime}(W)>0\right]$, but at lower rates $\left[U^{\prime \prime}(W)<0\right]$.

In order to illustrate this concept, imagine a person with an endowment of US\$ 1 million riskless. Someone offers him a lottery ticket with two possible outcomes:

- $50 \%$ chance to receive US\$ 1 million

- $50 \%$ chance to lose US\$ 1 million. 
Clearly the expected prise is zero and the expected wealth is the same to the initial one. Assuming $\mathrm{p}$ is the lottery prise:

$$
E\left(W_{0}+p\right)=0.5\left(W_{0}+1,000,000\right)+0.5\left(W_{0}-1,000,000\right)=W_{0}
$$

If the price of this lottery ticket is zero, then it would be a fair game, because the price would be equal to the expected payoff. But, because Jensen's inequality, which implies risk-aversion, one should not buy this ticket because he or she will increase riskiness with no improvement of expected final wealth. Rewriting Jensen's inequality:

$$
E\left[U\left(W_{0}+p\right)\right]<U\left[E\left(W_{0}+p\right)\right]=U\left[E\left(W_{0}\right)+E(p)\right]=U\left(W_{0}\right)
$$

The right hand side of the inequality, $U\left[E\left(W_{0}+p\right]\right.$, represents the utility of someone that has not bought the lottery ticket, because his or her utility continues to be $U\left(W_{0}\right)$, riskless. And the left hand side represents an agent's utility that bought the ticket but the payoff is still unknown. Figure 2 shows lottery A by the dotted line. In this lottery wealth will double or vanish, but the expected final wealth is. Due to the concavity of the utility function of a risk-averse agent, the ex-ante expected utility of wealth with the lottery ticket is lower than the one with no ticket, in spite of having the same ex-ante expected wealth.

Figure 2 Expected utility theorem (see online version for colours)

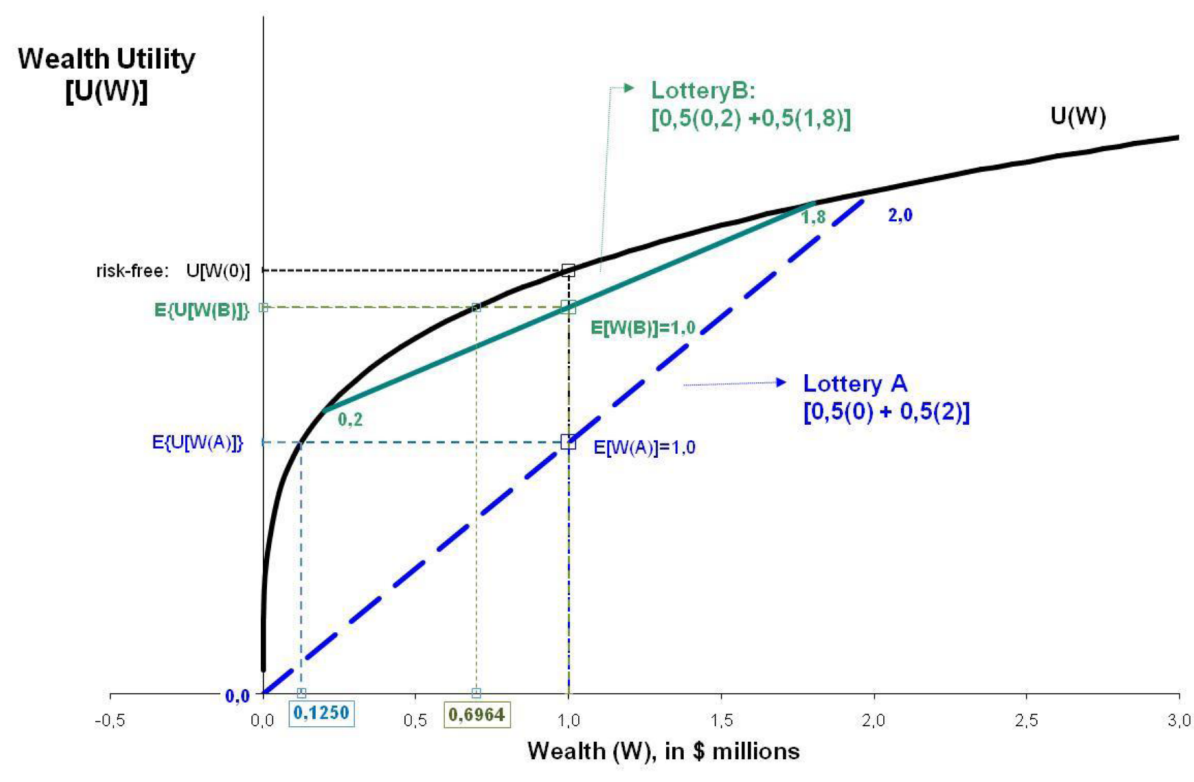

The agent who holds a lottery A ticket of would be willing to pay US\$ 875,000 [\$1 mi $-\$ 0.125 \mathrm{mi}]$ only to eliminate risk. Note that if it is done, he or she would stay in the same level of expected utility $E\{U[W(A)]\}$.

In lottery B (straight line), the better can gain or lose $80 \%$ of his initial wealth. So the final expected wealth remains the same US\$ 1 million. We can see that the expected utility of holding a lottery B ticket $[E\{U[W(B)]\}]$ is far better than holding the previous one, despite they have the same expected payoff (zero). An agent who holds a lottery B 
ticket is willing to pay US\$303,600 [1 $\mathrm{mi}-0.6964 \mathrm{mi}$ ] to eliminate risk, much less than the holder of lottery A ticket.

Lottery A is riskier than $\mathrm{B}$, because its probable payoffs are more dispersed and have greater standard deviation than $\mathrm{B}$. The standard deviation of $\mathrm{A}$ is US\$ 1 million $\left[0.5(-\$ 1 \mathrm{mi})^{2}+0.5\left(\$ 1 \mathrm{mi}^{2}\right]\right.$ and that of lottery B is US\$ 640,000 $\left[0.5(-\$ 0.8 \mathrm{mi})^{2}\right.$ $\left.+0.5(\$ 0.8 \mathrm{mi})^{2}\right]$.

So far it may seem that the expected utility theorem is well suited for insurance premiums, because we end up with the price (loss of wealth) people are willing to pay in order to avoid or at least mitigate risky outcomes. Next section we will show how this theorem can be applied in financial markets where ex-ante expected rate of return plays a key role on investment decisions.

\section{Expected utility theorem and ex-ante portfolio rate of return}

Assuming an agent could invest all his wealth in a risky portfolio which yields a random rate of return named $k$. According to the expected utility theorem we would have this relationship:

$$
U\left[W_{0}(1+\rho)\right]=E\left\{U\left[W_{0}(1+k)\right]\right\}
$$

$\rho$ is the certainty equivalent rate of return with respect the risky rate $k$. In order to study how $\rho$ relates itself to portfolio characteristics and agent's degree of risk aversion we use a Taylor expansion technique around the initial wealth $\left(W_{0}\right)$. So expanding the left-hand side of equation (4) we have:

$$
U\left[W_{o}(1+\rho)\right] \cong\left(\sum_{n=0}^{N} \frac{\left(\rho W_{o}\right)^{n} U^{(n)}\left(W_{o}\right)}{n !}\right)
$$

Equation (5) is not exact because it is missing the Lagrange remainder, which value is assumedly very small. Expanding the Taylor series up to $N=1$, and ignoring higher order terms, we have:

$$
U\left[W_{o}(1+\rho)\right] \cong U\left(W_{0}\right)+\rho W_{o} U^{\prime}\left(W_{0}\right)
$$

Applying a second order Taylor expansion on the right-hand side of equation (4) we get:

$$
E\left\{U\left[W_{0}(1+k)\right]\right\} \cong E\left\{U\left(W_{0}\right)+k W_{0} U^{\prime}\left(W_{0}\right)+\frac{\left(k W_{0}\right)^{2}}{2} U^{\prime \prime}\left(W_{0}\right)\right\}
$$

Assuming that the current level of wealth $\left(W_{0}\right)$ and its utility are already known, they can be considered as constants. Then applying the expectation operator $[E(\cdot)]$ to the terms of equation (7), we have:

$$
E\left\{U\left[W_{0}(1+k)\right]\right\} \cong U\left(W_{0}\right)+E(k) W_{0} U^{\prime}\left(W_{0}\right)+\frac{E\left(k^{2}\right) W_{0}^{2}}{2} U^{\prime \prime}\left(W_{0}\right)
$$

Substituting equations (6) and (8) into equation (4) we have:

$$
U\left[W_{o}(1+\rho)\right]=E\left\{U\left[W_{o}(1+k)\right]\right\}
$$




$$
\begin{aligned}
& U\left(W_{0}\right)+\rho W_{o} U^{\prime}\left(W_{0}\right)=U\left(W_{0}\right)+E(k) W_{0} U^{\prime}\left(W_{0}\right)+\frac{E\left(k^{2}\right) W_{0}^{2}}{2} U^{\prime \prime}\left(W_{0}\right) \\
& \rho W_{o} U^{\prime}\left(W_{0}\right)=E(k) W_{0} U^{\prime}\left(W_{0}\right)+\frac{E\left(k^{2}\right) W_{0}^{2}}{2} U^{\prime \prime}\left(W_{0}\right)
\end{aligned}
$$

Dividing both sides by $W_{o} U^{\prime}\left(W_{0}\right)$ :

$$
\rho=E(k)+\frac{E\left(k^{2}\right) W_{0}}{2}\left[\frac{U^{\prime \prime}\left(W_{0}\right)}{U^{\prime}\left(W_{0}\right)}\right]
$$

Let us assume that $k$ follows a geometric Brownian motion. This implies that $k$ follows a lognormal distribution with average $E(k)$ and standard deviation equal to $\sigma$. Thus mathematically the instantaneous percent change of wealth is modelled this way:

$$
\frac{d W}{W}=\frac{k W}{W}=k=\mu d t+\sigma \varepsilon \sqrt{d t}
$$

This equation states that instantaneous percentage rate of change of wealth is equal to $k$, which follows a geometric Brownian motion. The infinitesimal change of time $(d t)$ takes part in both terms in the right-hand side of equation (11), the drift ( $\mu$, regarded as constant here) and stochastic term. This last term models the volatility of $\mathrm{k}$, which is determined by the standard deviation ( $\sigma$, also regarded as constant here) and the random variable $\varepsilon . \varepsilon$ follows a standard normal distribution with mean zero and variance of $1[E(\varepsilon)=0$ and $\left.E\left(\varepsilon^{2}\right)=1\right]$ and it is not correlated to any other variable.

Thus the expected value of $k$ is:

$$
\begin{aligned}
E(k) & =E(\mu d t+\sigma \varepsilon \sqrt{d t}) \\
& =E(\mu d t)+E(\sigma \varepsilon \sqrt{d t}) \\
& =E(\mu d t)+\sigma E(\varepsilon) \sqrt{d t} \\
& =E(\mu d t)
\end{aligned}
$$

Since, $E(a b)=E(a) E(b)-\operatorname{Cov}(a, b)$, that $E(d t)=d t$ and covariance between $\mu$ and $d t$ is zero, we have:

$$
\begin{aligned}
& E(k)=E(\mu d t)=E(\mu) E(d t)-\operatorname{Cov}(\mu, d t) \\
& E(k)=\mu d t
\end{aligned}
$$

Therefore, if an agents' wealth is allocated in a portfolio which yields a rate of return $k$, the expected rate is $\mu$ at each infinitesimal time interval. It is worth noting that $\mu$ is equal to $E(k)$, the arithmetic average rate of return, in the discrete time we have:

$$
\mu=E(k)=\frac{\sum_{t=1}^{T} k_{t}}{T}
$$

and regarding $E\left(k^{2}\right)$ : 


$$
\begin{aligned}
E\left(k^{2}\right) & =E\left[(\mu d t+\sigma \varepsilon \sqrt{d t})^{2}\right] \\
& =E\left[\mu^{2}(d t)^{2}+2 \mu \sigma \varepsilon\left[(d t)^{3 / 2}\right]+\sigma^{2} \varepsilon^{2}(d t)\right]
\end{aligned}
$$

By convenience, we let drop out all the terms which has $d t$ elevated to a power greater than 1 , because these terms must be very small, we have:

$$
\begin{aligned}
E\left(k^{2}\right) & =E\left[\sigma^{2} \varepsilon^{2}(d t)\right] \\
& =\sigma^{2} E\left[\varepsilon^{2}\right] d t \\
E\left(k^{2}\right) & =\sigma^{2} d t
\end{aligned}
$$

And inserting this result into equation (10) we have got:

$$
\rho=E(k)+\frac{\sigma^{2} W_{0}}{2}\left[\frac{U^{\prime \prime}\left(W_{0}\right)}{U^{\prime}\left(W_{0}\right)}\right]
$$

From the assumption that agents have a concave function of utility of wealth we can state that term in brackets in equation (17) is negative. The denominator is positive, because it is an increasing function $\left[U^{\prime}(W)>0\right]$ and the numerator is negative because it increases at decreasing rates $\left[U^{\prime \prime}(W)<0\right]$. This term is the basis for Arrow-Pratt measure of absolute risk aversion $A(W)$, which has the following definition:

$$
A(W)=-\frac{U^{\prime \prime}(W)}{U^{\prime}(W)}
$$

Therefore, equation (17) can be rewritten as follows:

$$
\rho=E(k)-\frac{\sigma^{2}}{2} W_{0} A\left(W_{0}\right)
$$

Multiplying the absolute risk aversion function $A\left(W_{0}\right)$ by $W_{0}$ we get the relative risk aversion function, which is defined as follows:

$$
R(W)=W A(W)
$$

Rewriting (19) we get:

$$
\rho=E(k)-\frac{\sigma^{2}}{2} R(W)
$$

This is the definition of risk aversion that is most used when we study the behaviour of market prices, and this definition of risk aversion that will be used from now on.

\section{Portfolio selection between risk-free asset and equity market portfolio}

In this section we analyse how an agent can optimise portfolio in order to maximise his or her utility of wealth, given some investments opportunities. How much of his wealth should be invested in the equity market portfolio $(M)$ and how much in the risk-free asset $(f)$ ? 
We can rewrite equation (21) in order to emphasise the role of portfolio selection in this analysis simply adding a subscript in the appropriate variables:

$$
\rho_{p}=E\left(k_{p}\right)-\frac{\sigma_{p}^{2}}{2} R(W)
$$

The ex-ante expected rate of return is a weighted average of the expected rate of return of every asset which takes part in the portfolio. The weighting is determined by the proportion of the total value of the portfolio that is allocated to each component asset. In the case of two assets (sub-portfolios), we have:

$$
E\left(k_{p}\right)=w E\left(k_{M}\right)+(1-w) k_{f}
$$

$w$ is the percentage of the whole portfolio's value that is invested in $M$, the equity market portfolio. The remaining proportion of wealth $(1-w)$ is allocated to the risk-free asset.

The variance of a portfolio of two assets is obtained by the following equation:

$$
\sigma_{p}^{2}=\left(w \sigma_{M}\right)^{2}+(1-w) \sigma_{f}^{2}+2 w(1-w) \sigma_{M} \sigma_{f} \rho_{M, f}
$$

Since risk-free rate is assumed to have no risk, its variance and standard deviation is assumed to be nil. So equation (24) becomes:

$$
\sigma_{p}^{2}=\left(w \sigma_{M}\right)^{2}
$$

Inserting equations (23) and (25) into equation (22) we have:

$$
\rho_{p}=k_{f}+w\left[E\left(k_{M}\right)-k_{f}\right]-\frac{w^{2} \sigma_{M}^{2}}{2} R(W)
$$

Taking the derivative of the portfolio certainty equivalent rate of return with respect to $w$, equating it to zero, we get the optimum weight of the equity market portfolio $\left(w^{*}\right)$ :

$$
\begin{aligned}
& \frac{d \rho_{p}}{d w}=E\left(k_{M}\right)-k_{f}-w \sigma_{M}^{2} R(W)=0 \\
& w^{*}=\frac{E\left(k_{M}\right)-k_{f}}{\sigma_{M}^{2} R(W)}
\end{aligned}
$$

Since the agent is risk-averse, $R(W)>0$, then the second order condition for a maximum is satisfied:

$$
\frac{d^{2} \rho_{p}}{d w^{2}}=-\sigma_{M}^{2} R(W)<0
$$

In order to illustrate how equation (27) works suppose three agents have the same expectations with regard equity market rate of return, but they have different degrees of risk aversion from each other. Suppose the ex-ante expected equity portfolio rate of return is $25 \%\left[E\left(k_{M}\right)\right]$, the risk-free rate is $15 \%$, equity market portfolio volatility $(s)$ is $40 \%$. Knowing that the first agent has a relative risk aversion of 5 , the second of 2 and the third of only 0.75 , let us calculate [using equation (27)] the optimal weight portfolio for each one: 


$$
\begin{aligned}
& w_{R=5}^{*}=\frac{0.25-0.15}{0.4^{2}(5)}=12.50 \% \\
& w_{R=2}^{*}=\frac{0.25-0.15}{0.4^{2}(2)}=31.25 \% \\
& w_{R=0.75}^{*}=\frac{0.25-0.15}{0.4^{2}(0.75)}=83.33 \%
\end{aligned}
$$

Figure 3 depicts how these agents select their portfolio at the tangency points of the capital market line (CML) and their maximised indifference curves, which are the ones that maximise certainty equivalent rate of return (.) given CML data and their own risk aversion. On the vertical axis it is marked the certainty equivalent rate of return for each agent's portfolio, and the risk-free rate of $15 \%$.

Figure 3 Maximising utility for three different agents (see online version for colours)

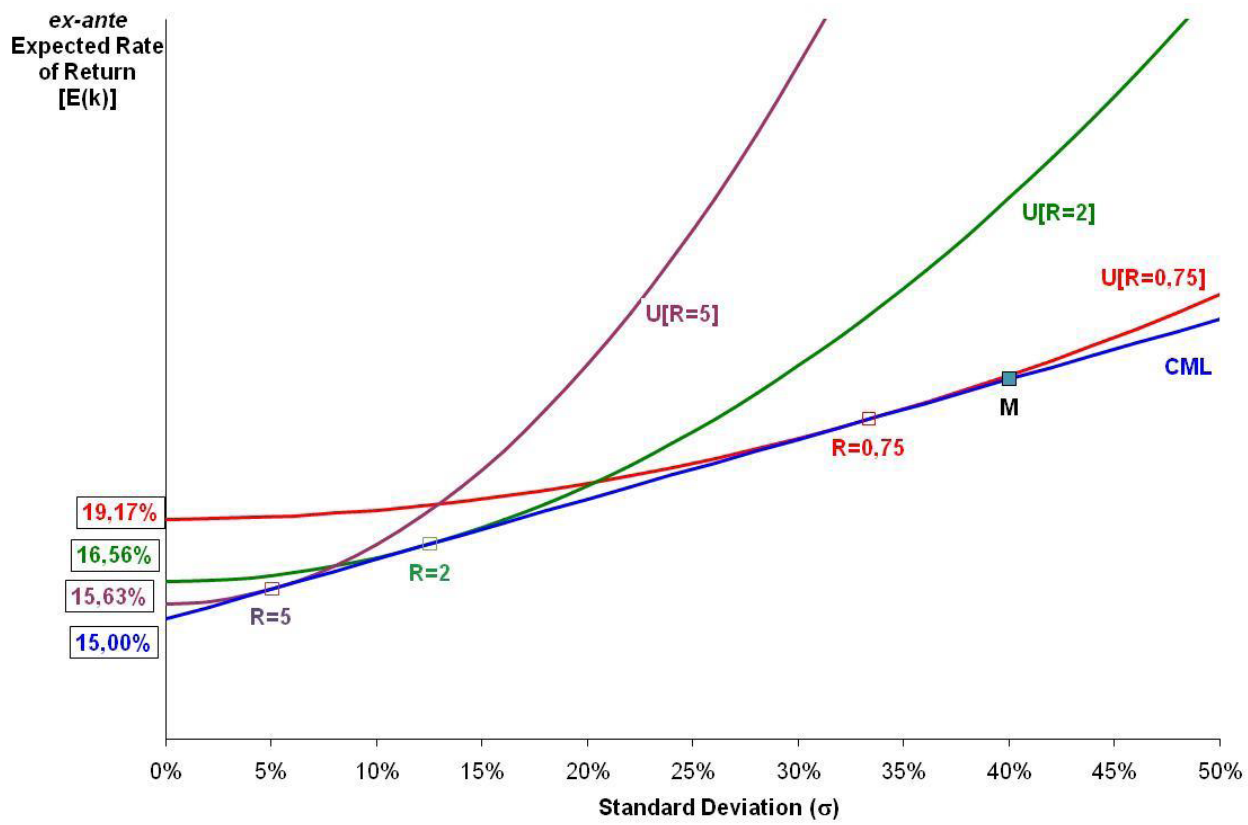

This is the basis to structure our methodology, which is presented in the next section.

\section{Estimating ex-ante expected rate of return based on Brazilian market data}

In order to estimate the ex-ante expected rate of return of the equity market portfolio, some simplifying assumptions are necessary. Analysing equation (27), we have (at least) three non-observable variables and just one equation. Without some assumptions it would be impossible to make any estimate. 
Firstly, we assume that markets are always efficient as a means of allocating wealth throughout the economy, respecting at the same time the expectations and degree of risk aversion of investors and resource takers. So we model a representative agent who has all the financial assets of the economy. In order to keep things simple, in this economy there is only the risk-free asset and the equity market portfolio. The decisions taken by the representative agent to buy or to sell assets reflect immediately in market prices.

These assumptions imply that the values of the risk-free asset and of equity market portfolio are always maximising the representative agent's utility. In other words, the way wealth is allocated is always the optimal $\left(w^{*}\right)$ respecting equation (27).

Unfortunately, we did not have the market value of all the stocks being traded on each day of our sample (ranging from 1 July 1994 to 18 November 2008). In order to have a proxy of the real weighting of the assets in the aggregate portfolio, we made some assumptions for parameters:

1 degree of risk aversion

2 market portfolio standard deviation

3 expected equity market risk premium.

With regard degree of risk aversion, we have a real trouble, even in markets like the USA. While the equity premium puzzle (Mehra and Prescott, 1985) is not solved it is difficult to establish any figure for this parameter. But using other studies cited by these two authors, the average degree of risk aversion has to be above zero and below 5 .

For standard deviation, it was used a daily basis measurement based on the maximum $\left(P_{t}^{M A X}\right)$ and minimum $\left(P_{t}^{M I N}\right)$ quote of the day and the closing quote of the previous day $\left(P_{t-1}\right)$. So the estimate of the daily volatility $\left(s_{d}\right)$ was defined by:

$$
s_{d}=\frac{1}{a}\left(\frac{P_{t}^{M A X}-P_{t}^{M I N}}{P_{t-1}}\right)
$$

The parameter $a$ was devised in order to match this estimation of volatility with the traditional approach, whose estimate of the standard deviation is based on observed ex-post rate of return. In order to match the average standard deviation of the whole period $a$ was set to 1.1386 . So the annual average standard deviation in annual basis is $39.08 \%$. So the daily volatility measured in annual basis for each day was calculated in the following way:

$$
s_{a}=s_{d} \sqrt{252}=\frac{1}{1.1386}\left(\frac{P_{t}^{M A X}-P_{t}^{M I N}}{P_{t-1}}\right)
$$

In order to start the 'experiment' we first set the initial conditions in 1 July 1994:

- For expected standard deviation of the rate of return of the market portfolio, we used the average annual standard deviation of the BOVESPA Index (IBOVESPA), which was calculated as $40 \%$ in annual basis.

- For initial ex-ante equity market risk premium, we define a rate higher than in the USA. Because Brazil is a riskier market. And we set it initially at $8 \%$ in annual basis.

- And finally, we assumed an average degree of relative risk aversion of 2. 
Applying these figures in equation (27) we can get the optimal weight of the equity market portfolio. Then, we assume that agent's total wealth is initially of 100 , that he invests $\left(100 w^{*}\right)$ in the IBOVESPA index and $[100(1-w)]$ in the risk-free asset (SELIC).

As time goes on, the ex-post rates of return are realised. For simplicity reasons, we assume that no Brazilian Treasury debt is issued or is paid, i.e., the aggregate debt increases only because of unpaid interest, which increases the investment of the representative agent in the risk-free asset.

Analogously, we assume that no new stock is issued and any dividend is used to purchase stocks immediately. So the amount invested in equity is determined as if the representative agent had a passive investment strategy.

So at time zero, [using equation (27)] the equity market portfolio was:

$$
w_{0}^{*}=\frac{E\left(k_{M}\right)-k_{f}}{\sigma_{M}^{2} R(W)}=\frac{.08}{\left(0.4^{2}\right) 2}=25 \%
$$

From time one on the weight of equity market portfolio is obtained by the ex-post rate of return of both assets, the risk-free $\left(k_{f, t}\right)$ and risky one $\left(k_{M, t}\right)$, by the following equation:

$$
w_{T}^{*}=\frac{100 w_{0}^{*} \prod_{t=1}^{T}\left(1+k_{M, t}\right)}{100 w_{0}^{*} \prod_{t=1}^{T}\left(1+k_{M, t}\right)+100\left(1-w_{0}^{*}\right) \prod_{t=1}^{T}\left(1+k_{f, t}\right)}
$$

We used the notation $w_{T}^{*}$ to emphasise that it is assumed that at any moment the efficient market maximises the representative agents' utility.

Rewriting equation (27) in order to estimate $E\left(k_{M}\right)$, we have:

$$
w_{T}^{*}=\frac{E\left(k_{M, T}\right)-k_{f, T}}{s_{a, T}^{2}[R(W)]} \Rightarrow E\left(k_{M, T}\right)=k_{f, T}+w_{T}^{*} s_{a, T}^{2}[R(W)]
$$

Other estimation is the equity risk premium, which is easily from equation (32).

The last estimation is the degree of risk aversion of the market. It is assumed that the 'true' standard deviation is constant $(=40 \%)$ and all the volatility around this figure is cause by changes in agent's risk aversion. This estimate uses the $E\left(k_{M, t}\right)$ calculated in equation (32) as an input in a rearrangement of the same equation (32):

$$
R(W)_{T}=\frac{E\left(k_{M, T}\right)-k_{f, T}}{w_{T}^{*}\left(s_{a, T}^{2}\right)}=\frac{E\left(k_{M, T}\right)-k_{f, T}}{w_{T}^{*}\left(0.4^{2}\right)}
$$

The next section presents the main results.

\section{Preliminary results and comments}

Using the same parameters mentioned last section $\left[R(W)=2 ; E\left(k_{M}-k_{f}\right)=8 \%\right.$ and $\sigma=40 \%$ ] we get the initial optimal weight $(w)$ for time zero equal to $25 \%$. Figure 4 shows the estimates of daily ex-ante expected rate of return of the equity market portfolio 
(IBOVESPA) in annual basis. It is worth noting that the vertical axis is in logarithm of base 2 , for convenience, in the three charts of this section.

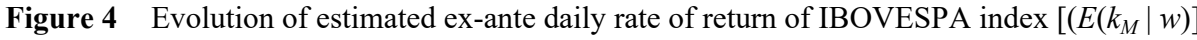
portfolio, its moving average for 21 working days, SELIC $\left(k_{f}\right)$ and IBOVESPA weight $(w)$ (see online version for colours)

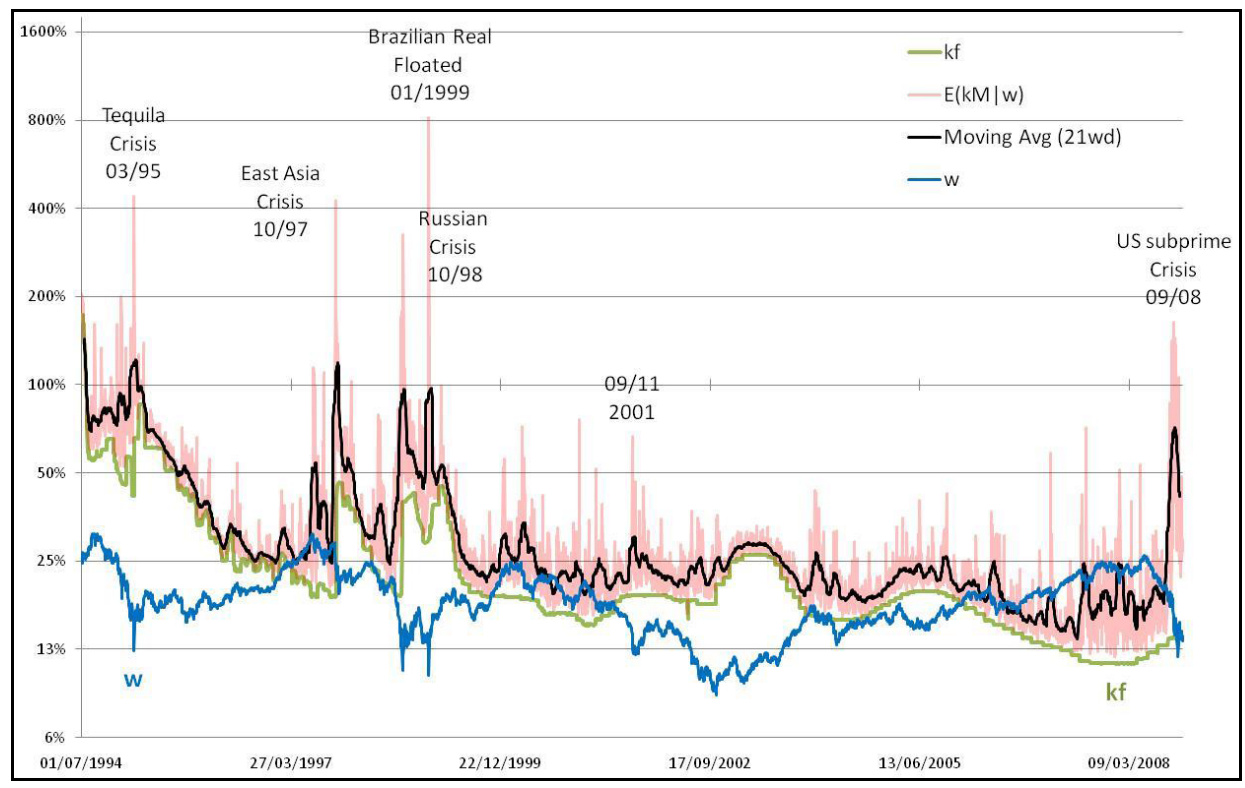

Figure 5 Evolution of estimated ex-ante daily equity risk premium (see online version for colours)

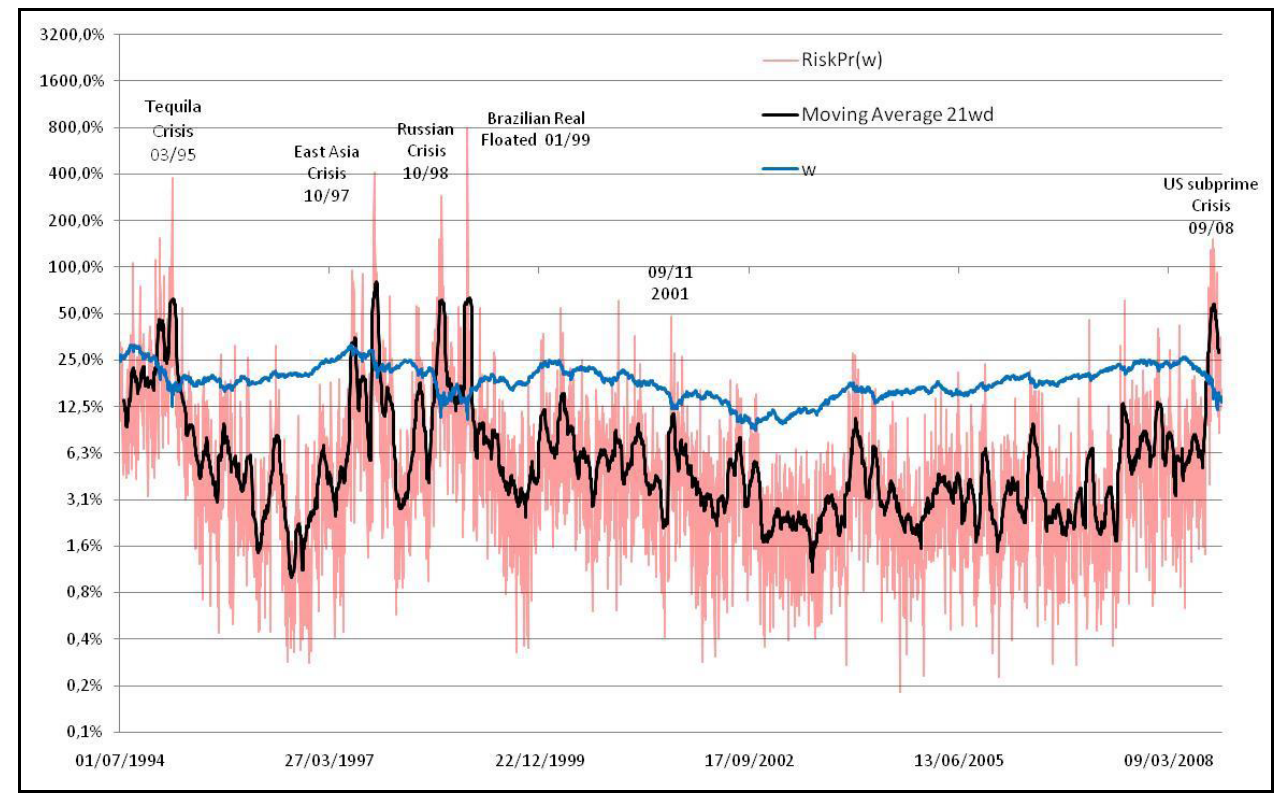


In Figure 4, we can see that the IBOVESPA weight in the aggregate portfolio (blue line), which goes up when the ex-post returns are higher than SELIC, wander in opposite direction of the ex-ante expected rate of return. This is predicted by financial models like CAPM.

Figure 5 shows how the estimated ex-ante equity risk premium changed along the period studied. In the charts of this section we used a moving average of only 21 days trading day, but it could have been longer and smoother.

If we assume that the 'real' standard deviation (risk) is constant over time, and the volatility observed in market is due humour changes of investor, i.e., relative risk aversion, then we can estimate how this parameter changes over time. That is what Figure 6 depicts.

Figure 6 Evolution of estimated relative risk aversion (see online version for colours)

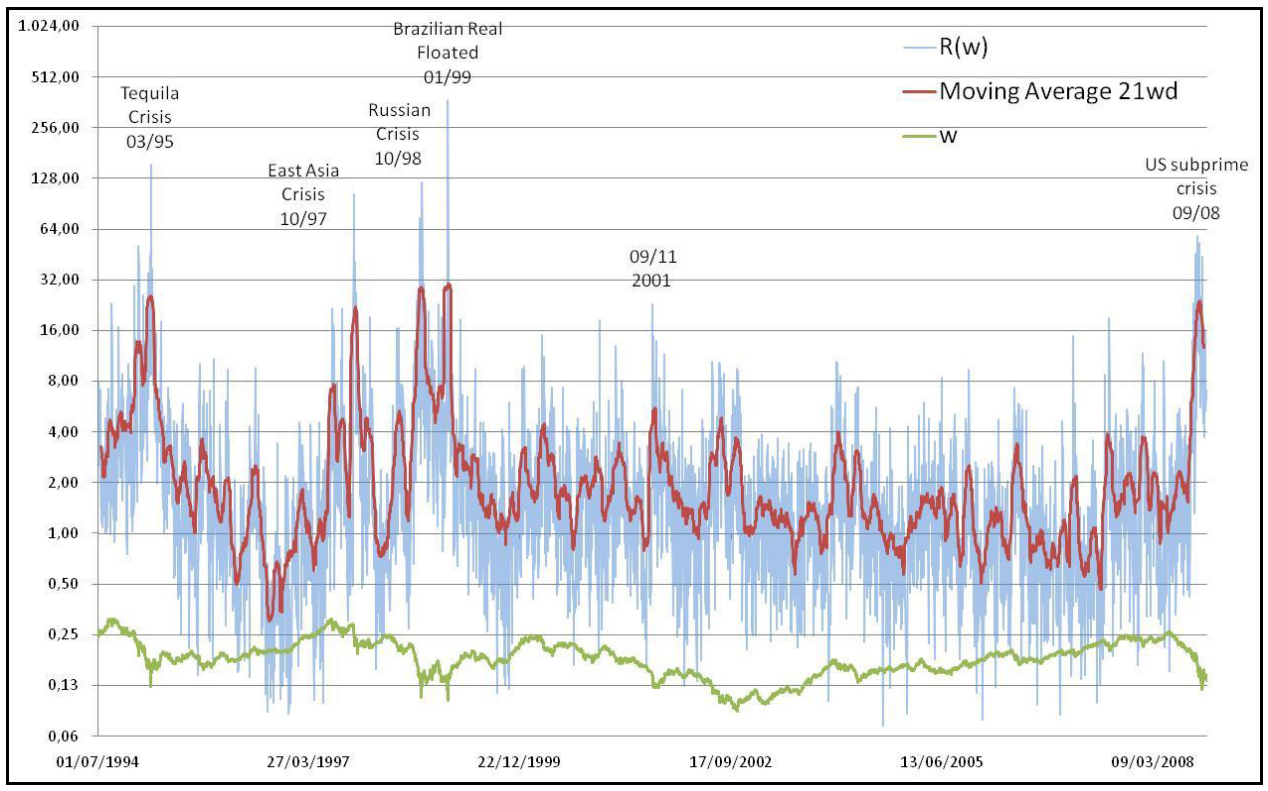

Because the equity premium puzzle is still unsolved, we should focus our study more in this subject in order to help us how to figure out how should be the ex-ante cost of capital of equity.

Many people believe that market efficiency makes prices reflect the 'fundamentals' of assets. But there is also an 'irrational' component of valuation which is how people deal with risk. In other words: degree of risk aversion.

We plan to expand this study including value and portfolio weights of individual assets in order to study how the market (the real 'representative agent') allocates capital throughout the economy. For this we have to take into account the securities issued, repurchased, payment of coupon/dividends, and daily quotations of closing, maximum and minimum prices.

And another front is to incorporate intertemporal constraints into our study, in order to figure out the relationship among financial and real economy variables. 


\section{References}

Campbell, J.Y., Lo, A.W. and Mackinlay, A.C. (1997) The Econometrics of Financial Markets, Princeton University Press, Princeton, NJ.

Mehra, R. and Prescott, E. (1985) 'The equity premium: a puzzle', Journal of Monetary Economics, Vol. 15, pp.145-161.

Plantin, G., Sapra, H. and Shin, H.S. (2008a) 'Marking to market: panacea or Pandora's box?', Journal of Accounting Research, Vol. 46, No. 2, pp.435-460.

Plantin, G., Sapra, H. and Shin, H.S. (2008b) Fair Value Accounting and Financial Stability, Research Paper No. 08-15, Graduate School of Business, University of Chicago [online] http://ssrn.com/abstract=1275395 (accessed 10/02/2008).

Von Neumann, J. and Morgenstern, O. (1944) Theory of Games and Economic Behavior, Princeton University Press, Princeton, NJ. 